\title{
The Contributions of Micro Small and Medium Enterprises in Rural-Urban Linkages in Wolaita Zone, South Ethiopia
}

\author{
Kataro Galasso Gamo ${ }^{1}$ Ramakrishna Gollagari ${ }^{2}$ \\ 1.Ph.D. Candidate, Ethiopian Civil Service University, Department of Urban Planning and Development \\ 2.Professor of Applied Economics, Ethiopian Civil Service University
}

\begin{abstract}
Development Policies and strategies of Ethiopia envisage micro small and medium enterprises as a strategic tool for strengthening rural-urban linkages and for bringing overall economic development and poverty eradication. This is due to the role of the enterprises in bridging urban and rural areas and the interdependence of the rural and urban economies in developing countries. However, the Ethiopian micro, small and medium enterprises do not seem to be on the right track in their relationship to the agricultural sector as required by the government policy and strategies. Most Ethiopian micro, small and medium enterprises are known for their high dependence on imported raw materials. Past studies failed to realize the potential benefits of creating production linkages by reinforcing rural-urban links across the country. The objective of this paper is to evaluate the capacity of micro, small and medium enterprises to forge rural-urban relationships that will assist in towards achieving the goals of GTP. The methodology for putting the paper together is by drawing results from the ongoing doctoral research ${ }^{1}$ by the author. The study is based on a concurrent triangulation mixed method approach using both quantitative and qualitative data with a questionnaire survey from 525 owners/managers of micro, small and medium enterprises as the main data collection tool. The study also collected qualitative data through informant interviews from $22 \mathrm{MSME}$ owners/managers. The research question addressed in this paper is what contributions can micro, small and medium enterprises play to strengthen rural-urban economic linkages? There is every reason to believe that micro, small and medium enterprises have the capacity to expand their demand for local agricultural raw material. Rural areas, on the other hand, have an equally reliable desire for agro-based products such as fertilizers, pesticides, and farming equipment. Unfortunately, the paper finds from the study that as high as 53.1 percent of micro, small and medium enterprises in the three administrative towns of Wolaita in south Ethiopia are wholly or partially dependent on industrial products and that only 1.5 percent appear involved in the production and supply of agricultural inputs. Extraordinarily, however, as much as 57.6 percent of the study's respondents chose the main reason hindering linkages as the unavailability of preferred and quality raw materials in the local market. In order to promote the linkage between the two sectors and areas, both the agricultural and MSME sectors productivity should be enhanced through improved agricultural productivity and enhancing the performance of small business sector to provide agricultural inputs through all rounded support of the government.
\end{abstract}

Keywords; Micro, Small and Medium Enterprises; Rural-Urban Linkage, Contributions, Wolaita Zone, South Ethiopia

DOI: $10.7176 / \mathrm{CER} / 11-4-01$

Publication date:May $31^{\text {st }} 2019$

\section{Introduction}

\subsection{Background of the Study}

Developing countries including Africa needs to enhance agricultural productivity to strengthen rural-urban linkages by providing raw materials for the industrial sector especially for small and medium manufacturing enterprises as well as to create new markets for manufactured consumer goods. Small and medium enterprises can equally play a greater role in the linkage through agricultural input provision and agricultural product utilization. According to the United Nations Industrial Organization (2011) report, African countries can exploit the potential complementarities between agriculture and industry through careful use of policies to promote a mutually beneficial relationship between them.

However, traditionally urban and rural areas have been viewed as exclusive and competing spheres placed in separate areas for planning, development and investment purposes (Tacoli, 2004). A simplified concept of rural and urban areas, with the words rural referring to more "remote farming areas" and urban to "crowded cities", has adopted by development policy and related research (von Braun, 2007). This view has facilitated the isolated treatment of issues affecting each space, and it has, as a result, failed to recognize the important socioeconomic development inter-linkages that exist between the two spaces and the many variants of the spaces.

Such approaches are the causes of failures of development planning due to lack of coordination between rural and urban development (regional) planning in developing countries including Ethiopia. Most of the development policies in developing countries are not considering the strong linkage between urban and rural areas. In reality, farming areas (the very rural) and the megacity (the very urban) coexist along a continuum with 
multiple types of flows and interactions happening between those two spaces (von Braun, 2007). Even though urban and rural areas are interdependent and coexist along a continuum, development debates and policies have been contested on either rural or urban priority in order to ensure socio-economic development in developing countries like Ethiopia (Gobaw, 2016).

In Ethiopia, during the regimes of Haile Selassie I and the Derge, development strategy was based on Import Substitution Industrialization (ISI) (Dorosh et al., 2011). This strategy gave emphasis to large industries neglecting the agricultural sector, small enterprises and the linked development between the agricultural sector and small enterprise. During that time, paradoxically, primacy was given to the industrial sector in a context where the economy still depended on agriculture for its capital accumulation, food supply, raw materials, foreign exchange generation, and market demand. That situation made the ISI strategy to be unsuccessful to promote the socioeconomic development of the nation due to its limited focus to the agricultural sector and the underdeveloped industrial sector. Moreover, under ISI, most of the expertise, know-how, equipment, and inputs were imported from abroad. Likewise, most of the profits also left the country in different forms and left hardly a sustainable effect on indigenous micro, small and medium enterprises (ECA, 1998 cited in Gebre-Egziabher and Demeke, 2005) and the agricultural sector.

On the contrary, the incumbent government of the Ethiopian People Revolutionary Democratic Front (EPRDF) in its Economic Development Policy gave priority to the prior development of agricultural sector by adopting a total shift from the industry to agriculture first strategy known as Agricultural Development Led Industrialization (ADLI) in 1993 (Dorosh et al., 2011). The objective of ADLI was and still is to strengthen the linkages between agriculture and industry by increasing the output of farmers, expanding large-scale private commercial farms, and by reconstructing the manufacturing sector in such a way that it can use the country's human and natural resources (Legesse, 2014). However, the great focus on agriculture resulted in a strategy that did not give enough attention to the nonagricultural sector and urban areas signifying that an urban development policy was not issued until 2005 (Dorosh et al., 2011). Dorosh et al. (2011) and Garoma (2012) note the challenge of focusing on rural areas and agriculture as a catalyst for industrialization. The authors indicated the inability of agriculture to feed and sustain the rapidly growing rural population, let alone to function as a catalyst for industrialization.

The output of many researchers and academics indicated that micro, small and medium enterprises (MSMEs) development in urban centers can immensely contribute to break regional imbalance and promote regional development of both urban and rural areas (Admire, 2014; Das, 2017). The enterprises established in urban centers are the ones, which enable them, perform their functions and shape the basis for their growth and development (Gebre-Egziabher and Demeke, 2005). Das (2017) notes the contribution of MSME sector, as an engine for socio-economic transformation of the country, is extremely essential in addressing the national objectives of bridging the rural-urban divide, reducing poverty and generating employment to the teeming millions of youth population. Due to their contributions, urban planners and academics in Sub-Saharan Africa have now acknowledged that the future of the region's competitiveness and socio-economic development depend on the MSMEs performance in urban centers of the region (Raftopolous, 2006 cited in Admire, 2014). Hence, it is necessary to verify the important contribution of MSMEs in bridging rural-urban divide.

The literature survey conducted by the researchers revealed that no study has been undertaken so far in the study area to examine the contribution of MSMEs in rural-urban linkages. This study argues that the development of MSMEs in Ethiopia is critical for the development of both rural and urban areas through strong rural-urban linkages. Therefore, this study is essential to fill the gap. The paper is structured into five sections; the introduction, literature review, methodology, findings and conclusion, and recommendation.

\subsection{Statement of the Problem}

Agriculture is the backbone of the Ethiopian economy as the sector that employs large populace, the source of raw materials for the urban expanding industries, the supply of food demand for an increasingly urban and rural population and export items, thus, creating strong rural-urban linkages (Legesse, 2014). It is in this light that the incumbent government of the FDRE has designed an ADLI strategy between rural and urban areas to attain rural-urban interlinked development. Cognizant of this fact, the Growth and Transformation Plan of Ethiopia (GTP) has been adopted to attain rapid industrialization and structural transformation as its core objectives with emphasis given to the expansion of MSMEs in all regions. Nevertheless, the existing sector has failed to fulfill the envisaged roles of transforming the economy and strengthening the rural-urban linkages. There is little evidence that Ethiopian micro, small and medium enterprises are aware of the huge opportunities that exist and can be realized under a truly structured and performing rural-urban economic integration. The core problem addressed in this paper is the failure of the Ethiopian micro small and medium enterprises to create forward and backward production linkages between agriculture and small enterprises and large enterprises and research and development institutions in larger urban centers such as to strengthen the rural-urban interdependent economy. It is generally expected that strong rural-urban and urban-urban linkages via MSMEs enhance the performance of 
the sector and can manifestly expand economic development and drastically cut poverty through job creation and capital formation.

\subsection{Objective of the Study}

The objective of this paper is to examine the contributions of micro, small and medium enterprises in strengthening rural-urban linkages in the context of dependence on locally produced agricultural raw material and, conversely, the role of these enterprises in providing agricultural inputs and domestically produced manufactured goods to the local farmers.

\subsection{Significance of the Study}

In the Growth and Transformational Plan (GTP) of Ethiopia, it is proposed that creating conditions for industry, especially micro, small and medium enterprises, to play a key role in the economy is of critical importance for economic development and poverty eradication by strengthening rural-urban linkages. In this context, the paper explores the role of the Ethiopian micro, small and medium enterprises in creating forward and backward linkages, considers factors hindering the linkages between enterprises and agriculture, and suggests measures to come out of the present situation. This goal of addressing such important socio-economic challenges underscores the significance of the paper.

\subsection{The scope of the Paper}

The paper follows the same locations of the main study namely, Wolaita Soddo, Areka, and Boditi towns. These administrative towns contain most of the micro, small and medium enterprises of Wolaita Zone in south Ethiopia with the largest being in Soddo, which is the capital of Wolaita Zone.

\section{LITERATURE REVIEW}

\subsection{The Concept of Rural-Urban Linkage}

Among the major concerns of developing countries are extreme poverty, unemployment, and economic growth. A number of studies have been conducted with the objective of identifying appropriate development strategies in these countries to bring sustainable development. The objective of this section is to review some of these studies and provide the conceptual framework for the study. Four strands of ideas focus on the development strategies that developing countries follow to solve their extreme poverty and unemployment problems. The issue of whether the same or different development strategies needed for developing countries and developed countries is still debated among development organizations, experts and policymakers.

One of the theories that argue about the development strategies of developing countries is the modernization theory. Modernization theory was developed in the mid-20th Century. Modernization is the term used for, the drastic transformation from the traditional society of the past to modern society as found in the west (Tettey, 2005). According to this author, modernization theory introduces modern methods of production like the use of advanced technology for industry. The underdeveloped countries might experience this modern technology to strengthen their economies and this will lead them to development. This theory holds that the modernization of states through economic development encourages other forms of development like social and political development. The theory assumes that the industrial structure in the developing countries will show a parallel development to what has happened in Europe and the USA (Gebre-Egziabher and Demeke, 2005). The authors also indicated the statement of modernization theory that production is concentrated in larger urban centers to exploit the agglomeration economies, thus, small enterprises are believed to disappear as the economy grows.

Modernization theory asserts that industrial employment attracts people to urban areas, where they work in modern sector employment that facilitates national economic expansion (Bradshaw, 1987; Tettey, 2005). According to these authors, urban areas contain modernizing institutions such as schools, factories, entertainment centers, and the mass media, as well as advanced medical care and these institutions then serve as a pull factor for the rural dwellers, encouraging them to migrate into the urban areas. Corbridge and Jones (2004) indicated the inclination of many developing countries to define development as a form of structural transformation seeking rapid transference from low paying, unproductive jobs in the countryside to more productive and better paying industrial jobs in urban centers.

The modernization theory is criticized by its inability to account for global south underdevelopment by a group of scholars collectively known as the dependency school, which originated in Latin America (Tettey, 2005). These opponents of the modernization theorists arrived at the formulation of the dependency theory as an alternative. The core idea of the dependency view is that Western capitalism cannot be entrusted with the advancement and industrialization of the poor countries. The relationship between the West and the global south is not at all beneficial to the latter. Evidence of this obvious asymmetry is the global south's persisting underdevelopment and reliance on the capitalist giants for capital, technology, and export product market. In dependency theory, micro, small and medium enterprises "survive either in direct dependency on the large 
enterprises or in other forms such as sub-contractors, petty producers and traders operate in extremely competitive markets with no possibility to earn profit sufficient to invest and grow" (Pederson, 1989).

Similarly, Akkoyunlu (2015) citing Singer (1964) indicated that in the 1950s and 1960s, 'modernization' was characterized as a shift of labor towards higher productivity sectors i.e., from agriculture to manufacturing and services. However, sluggish job creation in the non-agricultural sector and a failure to absorb the fastgrowing urban populations has led to a shift in emphasis back towards the agricultural sector through structural adjustment programmes designed to encourage crop production for export in the 1970s (Akkoyunulu, 2015). This failure of non-agricultural sectors and the assumption of scholars that government policy biased towards urban sectors led to urban bias theory.

Urban bias theory, on the other hand, led by Lipton (1977), argues that policies favor the urban areas to the disadvantage of the rural areas, hence the concentration of facilities and the creation of favorable conditions in the urban areas. One of the central ideas was that goods and services originating in rural areas were underpriced relative to a market 'norm'; goods and services flowing from urban areas were overpriced (Tettey, 2005). State policies allegedly overtax rural citizens with similar incomes. The production of the rural areas, notably agricultural products, is overtaxed due to price twists. Overtaxing works in the following way. State-controlled marketing boards buy agricultural products from the local farmers at an artificially low price and then resell these products to the consumers at the prevailing higher market price; the difference is often used to provide facilities in the urban areas.

In addition, governments in developing countries tend to invest domestic capital on the provision of development facilities. These facilities are largely located in the urban areas while a larger proportion of the population is found in rural areas. The facilities include hospitals, schools, libraries and other government/semigovernment facilities. Investable resource in favor of the rural dwellers, who are farmers, in the form of roads, small-scale irrigation facilities, agricultural machinery, and storage facilities are often downplayed by the policymakers. Higher standards of living are created in the urban areas resulting in the creation of disparity between the urban and the rural areas. As a result, rural dwellers tend to migrate to urban areas to take advantage of favorable policies.

Uribe-Echevarria (1991) showed that in the mid-seventies, the policy changed from the conceptual link between industrialization (urbanization) and inter-regional inequalities to inter-sectoral imbalances in regional development. According to the author, inter-regional disparities were considered the effect of the neglect of the agricultural sector, and their reduction was anticipated to come from new sectorial investment priorities. In this regional development policy, industry in general, large or small, no longer figured at the core of regional development. The priority of the policy was changed from employment and poverty to food production and rural development (Uribe-Echevarria, 1991). The gaps in income and employment opportunities between rural and urban areas were assumed to be narrowed by redressing resource allocation bias favoring urban development leading to reduce regional disparities (Lipton, 1977; Uribe-Echevarria, 1991). The limitation of this view was ignoring or had a negative view for the industrial sector and urbanization that is important for rural-urban economic linkages and not successfully addressed the problems of regional disparity. Based on these limitations and due to the complementary and supporting role of urban development towards agriculture initiated another alternative strategy that brings mutual or integrated development of the two spaces.

Corbridge and Jones (2004) mention the central place model in supporting the ' bias' in favor of the 'modern' encouraged the flow of innovation from bigger to smaller settlement as:

This 'bias' in favor of the 'modern' was encouraged by a body of work which suggested that innovations would flow from bigger to smaller settlements. The model of central places suggested that certain goods and services could be provided on a sustainable basis only by settlements of a given size or rank order. Small towns and rural areas could not expect to host major airports, for example, or large teaching hospitals. They simply did not have the customer base. It was always open to governments, of course, to try to develop regional growth poles in lagging regions (Corbridge and Jones, 2004 p.6).

Knivila (2007) indicated the importance of industrialization for economic growth and long-run poverty reduction supporting the idea of Corbridge and Jones, that governments of developing countries should make a big push for industrialization.

On the other hand, Kihonge (2014) ascertains that both the pro-urbanization view (modernization theory) and the pro-rural view (urban bias theory) are self-limiting and not benefiting the two areas, thus, the rural-urban continuum view brings in synergy or mutual benefit for the two spaces in rural-urban interaction. The flows and interconnections between rural and urban areas are justification for the rural-urban continuum views. Tacoli (2004) shows exchanges of goods and services between urban and rural areas as an essential element of ruralurban interactions. The interactions take many different forms "the flow of people (migration, commuting), capital (public and private) and goods (food, raw materials, and farm inputs), idea and innovation (farm and harvest techniques), information, environmental impact (uncontrolled urbanization) between the two 
areas"(Legesse, 2014). This situation blurred the space between the two areas, thus, development planning such as urban planning needs to consider the interaction of the two spaces together.

\subsection{Conceptual Framework}

The conceptual framework shows the mutually benefitting relationship between the Micro, small and medium enterprises in small and medium urban centers, large enterprises and research and development institutions in larger urban centers and agriculture in a typical rural-urban scenario. As the linkages between the agriculture, MSME and large enterprises and research and development institutions become strong, productivity could be enhanced in both sectors through strong rural-urban economic linkages.

Figure 1: Conceptual Framework of the Study

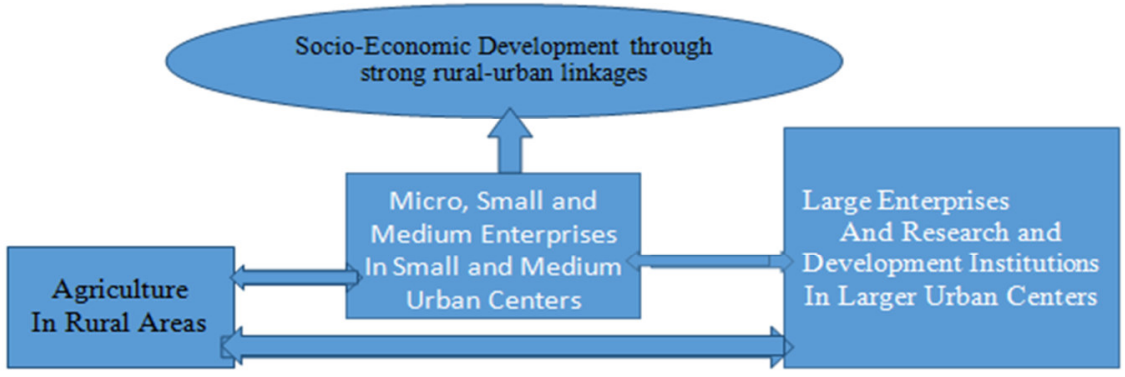

Source: Developed by the Researcher based on the Literature Reviewed, 2018

\section{RESEARCH METHODOLOGY}

This study is based on ongoing doctoral research by the author. The study has collected both primary and secondary data. Primary quantitative data collected from $525 \mathrm{MSME}$ owners/managers from the three administrative towns of Wolaita. Qualitative primary data collected by key informant interviews from 22 MSME owners/managers considerable information gathered there from providing the foundation for this paper. The paper uses selected variables to systematically address the basic research question: the dependent variable is strengthening the linkages between the micro, small and medium enterprises, and agricultural sector economic linkages and the independent variables are forward and backward production linkages and the level and type of outputs provided to the local farmers and the enterprises.

\section{Findings}

\subsection{Spatial Distribution of Enterprises}

Concerning the spatial distribution in the three urban administrations of the zone Figure, 2 presented $56.2 \%$ of the firms are in Wolaita Soddo town, 27.8\% in Areka and the remaining 16\% in Boditi town. The implication is that Wolaita Soddo town as a zonal center housed more than half of the firms. Figure 2 presents the distribution of MSMEs in the three sampled urban administrations of Wolaita Zone.

Figure 2: Distribution of the Sampled Firms in the Urban Administrations in Percent

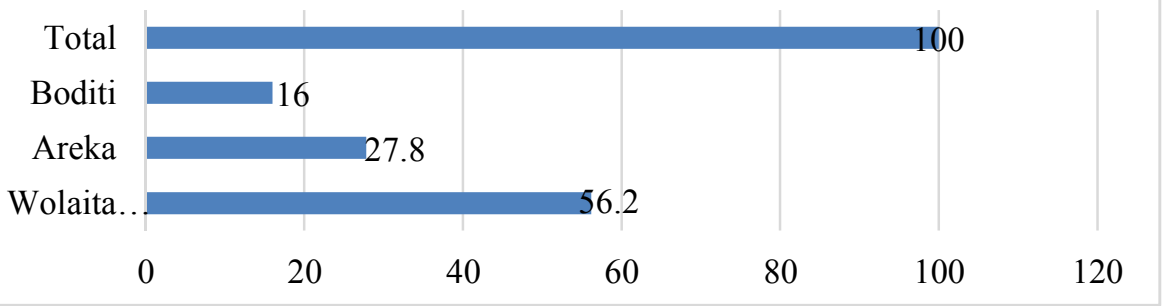

Source: Survey Result, 2018

AS it is presented in Figure2, distribution of the enterprise was not uniform in the urban centers. It was more predominant in Wolaita Soddo town as a zonal center, which accounted for more than half of the enterprises in the three biggest urban centers.

\subsection{Distribution of Firms in Sector}

This study adopted the sectoral breakdown based on the classifications used by researchers such as Liedholm and Mead (2002). These authors have found variations in enterprise and owner characteristics across sectors and used sector dummies in their analysis to take account of sectoral variations that would have an effect on a firm's performance. The World Bank report (2007), also analyzed the distribution of gender, education and other characteristics across sector composition based on data from CSA of Ethiopia, and posits that there are observable variations in these characteristics across the sector. Figure 3 shows the distribution of firms in terms 
of the sector in the sampled towns

Figure 3: Distribution of Firms in terms of Sector in Towns

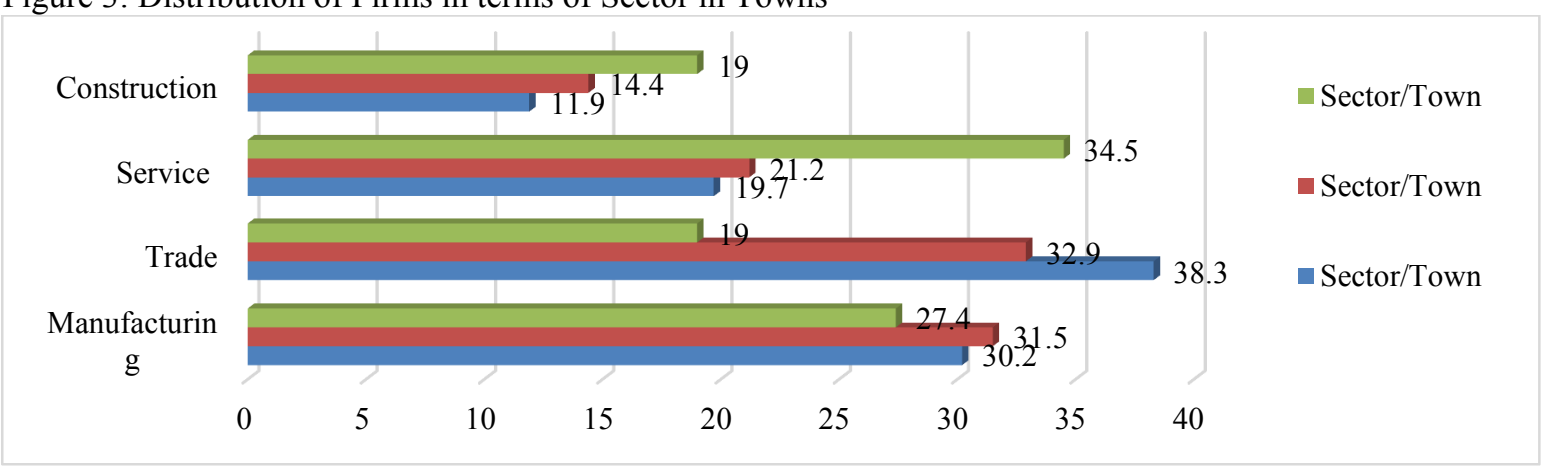

Source: Survey Result, 2018

According to the data, most of the firms are from the trade sector 38.2 percent in Wolaita Soddo, 32.9 percent in Areka and 19 percent in Boditi. However, in Boditi town 34.5 percent of the firms are from the service sector, 27.4 percent are from manufacturing and trade and construction sectors are 16 percent both. Most of the firms engaged in the trade sector, followed by manufacturing and service sector. This division of enterprises by sector is believed to be helpful to study each sectors critical factors that affect their performance.

\subsection{Distribution of Firms in Size}

The sample of respondents as a whole comprised of firms that were fairly micro in size in terms of size, measured by the number of employees with mean value 5.51 and a standard deviation of 4.28 . Using the firm classification in Ethiopia, the majority of the sample firms were micro enterprises, as illustrated in Figure 5. Likewise, the microenterprise in the trade sector comprised a greater proportion of the sample enterprise compared to the other sectors.

Figure 5: Distribution of Firms in Terms of Size and Sector

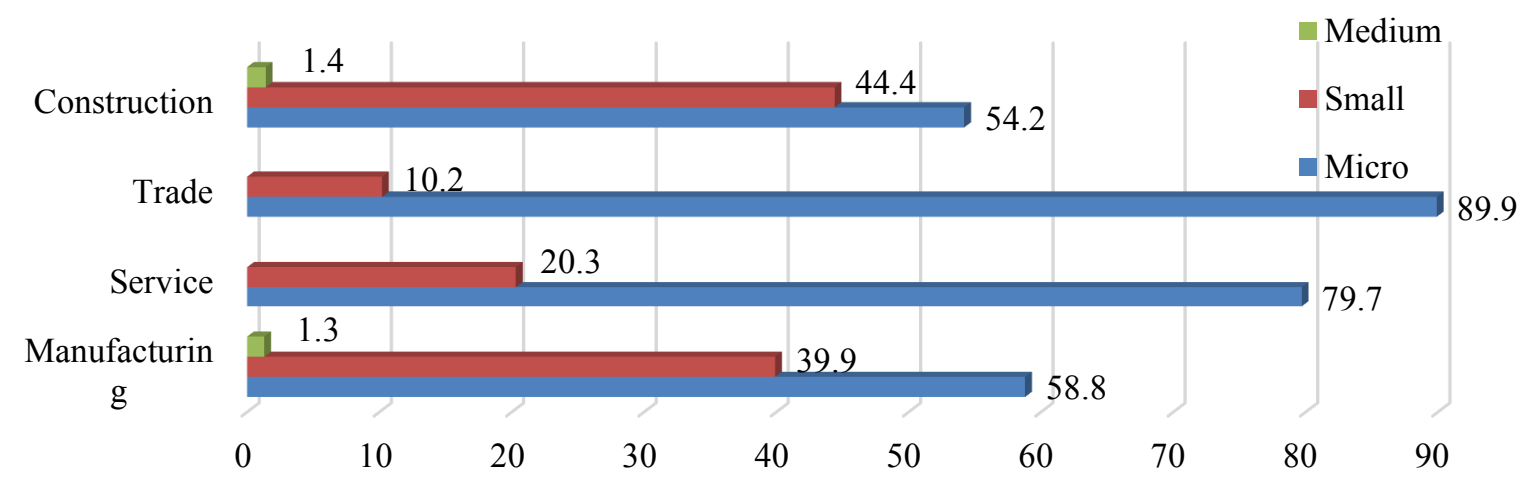

Source: Survey Result, 2018

Moreover, there were only three medium enterprises at the sample in terms of employees indicating the enterprises were only micro and small from which some of the enterprises are grown to medium size in terms of capital. This pattern of sample distribution in terms of size and sector was understandable as the lists of registered firms from the administrative towns in the Zone showed that micro enterprises comprised the majority of the total firms in the sampled urban administrations. The sample also showed that manufacturing sector comprised 30.1 percent of the sampled enterprises

\subsection{The contribution of Micro Small and Medium Enterprises in Rural-Urban Linkages}

This study was designed to examine the level of contribution of micro, small and medium enterprises in urban administrations of Wolaita Zone from the perspective of rural-urban linkages proxied by dependency on local raw materials for their input, provision of agricultural input, linkages with larger enterprises and research and development institutions. Table 1 presents the type of inputs used by enterprises by sectors. 
Table 1: Type of inputs used by Micro, Small and Medium Enterprises by Sector

\begin{tabular}{|c|c|c|c|c|c|}
\hline Types of Inputs & Manufacturing & Trade & Service & construction & Total \\
\hline Local farm produce & 10.8 & 7.3 & 9.3 & - & 7.8 \\
\hline Non-local farm produce & 1.9 & 2.8 & 1.7 & - & 1.9 \\
\hline Local and non-local farm produce & 8.9 & 5.6 & 17.8 & 1.4 & 8.8 \\
\hline Industrial products & 44.3 & 70.6 & 59.3 & 19.4 & 53.1 \\
\hline Locally available raw materials & 3.2 & 7.9 & 5.1 & 25.0 & 8.2 \\
\hline Others (Specify) & 27.8 & 1.7 & 2.5 & - & 9.5 \\
\hline $\begin{array}{l}\text { Industrial products and Locally available raw } \\
\text { materials }\end{array}$ & .6 & 4.0 & 4.2 & 54.2 & 9.9 \\
\hline $\begin{array}{l}\text { Local farm produce and Locally available raw } \\
\text { materials }\end{array}$ & 2.5 & - & - & - & 0.8 \\
\hline Total & 100 & 100 & 100 & 100 & 100 \\
\hline
\end{tabular}

Source: Survey Result, 2018

Table 1 above presented that $10.9 \%$ of the manufacturing sector, $7.3 \%$ of trade and $9.3 \%$ of service sector use local farm products as their inputs. However, none of the construction sectors uses local farm products. Regarding industrial products, $44.3 \%$ of manufacturing, $70.6 \%$ of trade, $59.3 \%$ of the service sector and 19.4 people of construction sector use industrial products as their input.

One of the dimensions of rural-urban linkages of micro, small and medium enterprises with the agricultural sector is the use of agricultural produce as input for enterprises as a raw material. Table 2 presented that $53.1 \%$ of the enterprises are dependent on industrial products, $18.9 \%$ use industrial products and locally available raw materials as inputs for their businesses. A very small number of enterprises (i. e., $7.8 \%$ ) use local farm produce, $1.9 \%$ of enterprises use non-local farm produce indicating the dependence of enterprises on the agricultural product for their input is low. Table 2 presents the types of inputs used by enterprises.

Table 2: Type of inputs used by Micro, Small and Medium Enterprises by administrative Towns

\begin{tabular}{lcccc}
\hline \multicolumn{1}{c}{ Firms Input } & Wolaita Soddo & Areka & Boditi & Total \\
Local farm produce & 2.7 & 4.4 & 0.8 & 7.8 \\
Non-local farm produce & 1.3 & 0.6 & - & 1.9 \\
Local and non-local farm produce & 5.1 & 2.1 & 1.5 & 8.8 \\
Industrial products & 27.2 & 5.2 & 10.7 & 53.1 \\
Locally available raw materials & 5.5 & 2.5 & 0.2 & 8.2 \\
Others (Specify) & 0.8 & 0.2 & 0.2 & 1.1 \\
Industrial products and Locally available raw materials & 13.3 & 2.9 & 2.7 & 18.9 \\
Local farm produce and Locally available raw materials & 0.2 & - & - & 0.2 \\
Total & 56.2 & 7.8 & 16 & 100 \\
\hline
\end{tabular}

Source: Survey Result, 2018

As indicated by Table 1 and Table 2 most of the enterprises depend on industrial products as input for their firms. This result indicates that backward linkages of enterprises with local agricultural sector are insignificant. The key informant's interview result also shows $12(54.5 \%)$ of the firms from the total 22 interviewed use industrial products, $7(31.8 \%)$ use locally available raw materials and industrials products and the balance 3 $(13.6 \%)$ use local farm products. Thus, the situation in administrative towns of Wolaita Zone does not seem different from what is indicated by Gebre-Egziabher and Demeke (2007) in small towns of Amhara region. Therefore, the results from both the survey and key informant interview show that local agricultural products have a limited market in the zone. The local and external linkages of micro, small enterprises could be examined in terms of the sources of raw materials and market places for their output goods and services.

Concerning sources of firm's inputs, the sampled owners/managers of enterprises indicated that 23.2 percent indicated outside the Zone but National, 17 percent indicated outside the zone but national and imported, 15.6 percent indicated local, and 6.5 percent indicated zonally. Table 3 presents sources of raw materials for firms in administrative towns of Wolaita Zone. 
Table 3: Sources of Firms Inputs/Raw Materials

Source of Inputs
Local
Zonal
de the Zone but National
Imported
Local and Zonal

Zonal and outside the zone but National

Outside the zone but national and Imported

Local and outside the zone but national

Local, zonal and outside the zone but national

Local, zonal, outside the zone and imported Total

\begin{tabular}{ccc} 
Frequency & Percent & Cumulative Percent \\
82 & 15.6 & 15.6 \\
34 & 6.5 & 22.1 \\
122 & 23.2 & 45.3 \\
27 & 5.1 & 50.5 \\
70 & 13.3 & 63.8 \\
43 & 8.2 & 72.0 \\
89 & 17.0 & 89.0 \\
20 & 3.8 & 92.8 \\
23 & 4.4 & 97.1 \\
15 & 2.9 & 100.0 \\
525 & 100.0 & \\
\hline
\end{tabular}

Source: Field Survey Result, 2018

The qualitative data result from key informant interview also shows that from the total 22 MSME owners/managers interviewed from the three administrative towns of Wolaita Zone, 10 (45.5\%) reported national, $7(31.8 \%)$ reported local and imported, $3(13.6 \%)$ reported local and balance $2(9.1 \%)$ reported local and national for the source of their firm inputs. As it is acknowledged both in quantitative and qualitative data, it is clear from the results that the main sources of raw materials are outside the zone and the region (national) which is imported and final finished industrial product showing the low dependence of firms in local raw materials.

Concerning firms that depend on local raw materials, the respondents indicated the average distance of the local raw materials in kilometers from their firm. Table 4 presents the average distance of the local source raw materials in kilometers from their firm location.

Table 4: Distance of Local Raw Materials from MSMEs Location

\begin{tabular}{|c|c|c|c|c|}
\hline \multicolumn{2}{|c|}{ Distance of Raw Material } & Frequency & Percent & Cumulative Percent \\
\hline \multirow{4}{*}{ Valid } & $<50 \mathrm{~km}$ & 146 & 65.5 & 65.5 \\
\cline { 2 - 5 } & $50-100 \mathrm{~km}$ & 31 & 13.9 & 79.4 \\
\cline { 2 - 5 } & $101-150 \mathrm{~km}$ & 18 & 8.1 & 87.5 \\
\cline { 2 - 5 } & $151-200 \mathrm{~km}$ & 2 & 0.9 & 88.4 \\
\cline { 2 - 5 } & $201-300 \mathrm{~km}$ & 10 & 4.5 & 92.9 \\
\cline { 2 - 5 } & $301-400 \mathrm{~km}$ & 14 & 6.3 & 98.2 \\
\cline { 2 - 5 } & $401-500 \mathrm{~km}$ & 1 & 0.4 & 99.6 \\
\cline { 2 - 5 } & $>500 \mathrm{~km}$ & 1 & 0.4 & 100 \\
\cline { 2 - 5 } & Total & 223 & 100 & \\
\hline
\end{tabular}

Source: Field Survey Result, 2018

Table 4 illustrated that 65.5 percent of the respondents indicated that micro, small and medium enterprises were receiving their local raw materials from sites less than 50 kilometers away. 13.9 percent of enterprises from 50 to 100 kilometers, 8.1 percent from sites 101 to 150 kilometers, while the balance 12.5 percent were receiving their local raw materials from locations more than 150 kilometers.

The respondents were also asked to indicate the trend of dependency on non-local raw materials. The results indicated on Table 5 clearly reveal that 36.4 percent of the respondents indicated their dependency on non-local raw materials had been increasing, 26.7 percent maintained their non-local raw materials use, and 24 percent suggested that their dependency on non-local raw materials had been highly increasing. From the remaining 12.5 percent, 4.4 percent indicated declining and 8.5 percent indicated highly declining. Table 5 shows the trends of dependency of firms on non-local raw materials.

Table 5: Trends of Dependency on Non-Local Raw Materials

\begin{tabular}{cccc} 
Trend & Frequency & Percent & Cumulative Percent \\
Highly Declining & 15 & 4.4 & 4.4 \\
Declining & 29 & 8.5 & 12.9 \\
Neutral & 91 & 26.7 & 39.6 \\
Increasing & 124 & 36.4 & 76.0 \\
Highly Increasing & 82 & 24 & 100.0 \\
Total & 341 & 100.0 & \\
\hline
\end{tabular}

Source: Field Survey Result, 2018

Concerning factors that lead to dependency on non-local raw materials, Table 6 below shows the reason for dependency on non-local raw materials. 28.8 percent of the owners/managers answered that the unavailability of the raw materials in the local market was the case, 28.8 percent to search for better quality of the raw materials, 29.3 percent indicated that insufficient quantity of the raw materials and the remaining 13.1 percent were the 
combined cases of these three reasons.

The result shows a big gap in enterprises linkages to the agricultural sector and other sources of local raw materials for the zone's economy to take advantage of it. This result is similar to the study of Legesse (2014), found a huge gap in industrial linkages of medium and large scale manufacturing industries in industrial zones of Ethiopia to the agricultural sector and other sources of raw materials for the country's economy. Table 6 presents the major factors leading MSMEs to depend on non-local raw materials for their input in sampled firms of administrative towns in Wolaita Zone.

Table 6: Factors that Lead to Dependency on Non-Local Raw Materials

$$
\text { Factors }
$$

Due to the unavailability of the raw materials in the local market

To search for better Quality

Due to the insufficient quantity of the raw material in the local market

Others

Due to unavailability of raw materials and to search for better quality

To search for better quality and Due to the insufficient quantity of the raw material in the local market

Due to unavailability of raw materials and Due to insufficient quantity of the raw material in the local market

Total

\begin{tabular}{rr} 
Frequency & Percent \\
109 & 28.8 \\
109 & 28.8 \\
111 & 29.3 \\
5 & 1.3 \\
20 & 5.3 \\
15 & 3.9 \\
10 & 2.6 \\
& \\
379 & 100.0 \\
\hline
\end{tabular}

Source: Field Survey Result, 2018

Concerning customers of the enterprise's Table, 7 presented the customers for the product and service of the enterprises. The result showed that 68.8 percent of respondents indicated that both farmers and town dwellers' as their customer, 29.9 percent reported that town dwellers, 1.1 percent indicated farmers and 0.2 percent reported others such as visitors. Therefore, the agricultural sector is also an important source of market for micro, small and medium enterprises since 68.8 percent of the owners/managers rely on both farmers and town dwellers as their customers. Table 7 presented customers for products and services of sampled enterprises in administrative towns of Wolaita Zone.

Table 7: Customers for Micro, Small and Medium Enterprises

\begin{tabular}{ccccc}
\hline & Customers & Frequency & Percent & Cumulative Percent \\
Farmers & 6 & 1.1 & 1.1 \\
Valid & Town Dwellers & 157 & 29.9 & 29.9 \\
& Both farmers and town dwellers & 361 & 68.8 & 68.8 \\
& Others & 1 & .2 & .2 \\
Total & 525 & 100.0 & 100.0 \\
\hline
\end{tabular}

Source: Field Survey Result, 2018

The qualitative data result from key informants interview also shows that from the total 22 MSME owners/managers interviewed from the three administrative towns of Wolaita Zone, 9 (40.9\%) reported urban dwellers, $10(45.5 \%)$ reported farmers and urban dwellers and the balance $3(13.6 \%)$ reported farmers, urban dwellers, and visitors as the customers of their firm products/services. As indicated both in quantitative and qualitative data results, it is clear that the main sources of the market for firms' products/services in the zone were farmers and urban dwellers of the zone.

Regarding the destination of outputs of enterprises were designated as local, zonal, regional, national and international for exporting firms. Table 8 shows that 40.8 percent of the enterprises has local and zonal markets, 39.6 percent of the enterprises have an only the local market, and 7.8 percent have an only zonal market. Totally about 88.2 percent of the businesses have a local and zonal market while only 11.8 percent provide their output outside the zone. 
Table 8: Destination of Outputs of Micro Small and Medium Enterprises

\begin{tabular}{cccc}
\hline Destination of Outputs & Frequency & Percent & Cumulative Percent \\
Local & 208 & 39.6 & 39.6 \\
Zonal & 41 & 7.8 & 47.4 \\
Regional & 4 & .8 & 48.2 \\
National & 2 & .4 & 48.6 \\
International & 1 & .2 & 48.8 \\
Local and Zonal & 214 & 40.8 & 89.5 \\
Regional and National & 4 & .8 & 90.3 \\
Local, Zonal and Regional & 36 & 6.9 & 97.1 \\
Local, Zonal, Regional and National & 6 & 1.1 & 98.3 \\
Zonal and Regional & 9 & 1.7 & 100.0 \\
Total & 525 & 100.0 & \\
\hline
\end{tabular}

Source: Field Survey Result, 2018

The qualitative data result from key informant interview also shows that from the total $22 \mathrm{MSME}$ owners/managers interviewed from the three administrative towns of Wolaita Zone, $19(86.4 \%)$ reported zonal and the remaining $3(13.6 \%)$ reported local, zonal and regional as the destination of their products/services. As it is illustrated both in quantitative and qualitative data, it is clear from the results that the main destination of the products of the firms' was the zone.

Therefore, the national and international market is very insignificant for the sampled enterprises operating in the administrative towns of the zone. This result is in line with Gebre-Egziabher and Demeke (2007) that businesses operating in small towns of Amhara region have a very insignificant national market. Similarly, the fact that 88.2 percent of micro, small and medium enterprises supply their products and services to local and zonal markets indicate that these enterprises depend on the income of the farmers and town dwellers of the zone. As a result, regional, national and international markets cannot be the sources of growth for the enterprises similar to the finding of Gebre-Egziabher and Demeke (2007).

Regarding the provision of inputs for the agricultural sector, only a very small number of enterprises are engaged in providing inputs for the sector. Table 9 shows that only $8(1.5 \%)$ of the total surveyed 525 enterprises reported input provision to farmers. The remaining 98.5 percent were not providing inputs to farmers. Therefore, from this result, the linkage of enterprises with the agricultural sector in terms of provision of agricultural input is not well developed. Table 9 presented the provision of agricultural inputs for local farmers by sampled enterprises in administrative towns of Wolaita Zone.

Table 9: Provision of Agricultural Inputs by Enterprises

\begin{tabular}{ccccc}
\hline \multirow{3}{*}{ Valid } & & Frequency & Percent & Cumulative Percent \\
& Yes & 8 & 1.5 & 1.5 \\
& No & 517 & 98.5 & 100.0 \\
& Total & 525 & 100.0 & \\
\hline
\end{tabular}

Source: Field Survey Result, 2018

The qualitative data result from key informants' interview of 22 selected MSME owners/managers from the three administrative towns indicates that they are not providing agricultural inputs for local farmers. In addition to the primary data, the secondary data from CSA (2012) also indicated that $45.7 \%$ of medium and large scales manufacturing industries of Ethiopia are agro-based with potential for promoting production linkages with the agricultural sector. Nonetheless, another CSA (2013) report pointed out that a majority of the agro-based firms are highly dependent on imported raw materials.

Regarding linkages created with large firms, and research and development institutions, Table 10 shows that 90.5 percent and 93.5 percent of the respondents indicated no linkages with large firms and research and development institutions respectively. The result indicates that enterprises in the Zone did not use the potential of larger firms and research and development institutions to enhance skills and innovation in their productivity. Table 10 illustrates the linkages of micro, small and medium enterprises with large enterprises and R\&D institutions in administrative towns of Wolaita Zone.

Table 10: Linkages of Enterprises with Large Firms and Research and Development Institutions

\begin{tabular}{ccccc}
\hline & Linkage with Large Firms & Linkage with Research and & Development Institutions \\
Response & Frequency & Percent & Frequency & Percent \\
Yes & 50 & 9.5 & 34 & 6.5 \\
No & 475 & 90.5 & 491 & 93.5 \\
Total & 525 & 100.0 & 525 & 100.0 \\
\hline
\end{tabular}

Source: Field Survey Result, 2018

From the qualitative data result of the total 22 respondents interviewed, $18(81.8 \%)$ reported that there is no 
linkage and the balance $4(8.2 \%)$ indicated a weak linkage between MSMEs, and large firms and R\&D institutions. In this regard, the key informants in qualitative research from the 22 selected MSME owners/managers from the three administrative towns of Wolaita Zone indicated that the linkages between MSMEs and large firms and R\&D institutions were insignificant.

Thus, both quantitative and qualitative results point out that the enterprises in the Zone did not use the potential of larger firms and research and development institutions to enhance skills and innovation in their productivity, which are useful for their performance. This result is in sharp contrast to small firms in other emerging regions such as in Asia whose linkages between small and larger firms is so strong that it added to the performance of the firms and general competitiveness of the economy (Liedholm and Mead, 2002). In these countries, larger enterprises create a big demand for smaller firms. Concerning linkage with Research and Development Institutions, for example, an investment in research and development may enable a firm to engage in new methods of production, which would enhance its future revenue (Garoma, 2012). However, MSMEs in administrative towns of Wolaita Zone have little investment in research and development, which hamper their engagement in a new method of production.

According to Liedholm and Mead (2002), linkages between small and large firms in Africa are very much limited. The researchers further argue that MSMEs sale their products to final consumers than to firms and traders in these countries. These authors further argue that MSEs in these areas that sell to traders and manufacturing firms are more likely to grow than those that sell directly to final consumers and hence the growth of these enterprises is reduced. Therefore, a lack of competitiveness among larger firms in Africa has hampered linkages and subcontracting arrangements with smaller firms. The nature of MSMEs clustering in Africa is that independent firms in the same industry are selling similar goods to the final consumer than traders and larger manufacturing. Hence, clusters in Africa are competing over the same demand than complementing each other in supplying inputs and other required resources and selling their products for traders and larger firms.

\section{Conclusions and Recommendations}

The paper sought to assess the contribution of micro, small and medium enterprises to forge beneficial linkages between the rural agricultural sector and urban business sectors to bring about increased economic production and, thereby, reduce poverty through employment creation and capital accumulation. Generally, it is believed that the Ethiopian economy will benefit greatly once the rural economy is effectively linked to the urban to create an efficient transfer and exchange system of support for agricultural products as raw material for industrial production. Conversely, an expanding agricultural sector will impose profitable demands on small businesses of a range of products needed for farming and general rural use.

The greatest concern, therefore, is why micro, small and medium enterprises in the country have not met the objectives of the GTP by creating employment and generating wealth through strong rural-urban linkages. Another concern raised in the paper deals with the capacity of micro, small and medium enterprises to integrate with research and development institutions to enhance their capacity by technology transfer and skills development as additional effort to strengthen rural-urban linkages. Clearly, it can be concluded that Ethiopian micro, small and medium enterprises are not playing a significant role expected of them under the ADLI strategy, urban development policy, and GTP to contribute to the development of the economy and alleviate poverty by strengthening rural-urban linkages. However, it must not also be overlooked that one of the major reasons influencing the enterprises from integrating backward in their production chain is the unavailability and quality of raw materials in the local market.

The paper sees a concerted re-awakening of policy-makers, farmers, enterprises, urban managers and planners, and the investment community to the invaluable potentials of a sustainable harmony between small enterprises and agricultural sector under a strengthened rural-urban economic linkage as quickest solution to poverty eradication through employment creation and wealth generation. It also minimizes the burden of larger towns by minimizing the migration of people from rural areas by creating employment opportunity by nearby towns. The following are hereby suggested as recommendations:

$>$ Enhance agricultural productivity and quality of raw material for firms input.

$>$ Enhance local demand through improved agricultural productivity in the region and increase the incomes of the town dwellers

$>$ Create market linkages for the enterprises to tap the regional and national export markets in their surrounding or larger urban centers including Addis Ababa.

$>$ In future industrial clustering, the location of agro-based industries should be based on the resource potentials of localities.

$>$ Provision of infrastructure within the industrial zone as well as expanding into the hinterland to strengthen the rural-urban linkages. 


\section{References}

Admire, M. (2014). An assessment of the role of spatial planning in the promotion of small and medium enterprises in small urban centers: Case of Shamva and Mazowe districts. Msc Thesis, University of Zimbabwe

Akkoyunlu, S. (2015). "The potential of rural-urban linkages for sustainable development and trade". International Journal of Sustainable Development \& World Policy, 4(2), 20.

Central Statistical Agency. (2013) Quarterly manufacturing Industry Business Survey. Fourth Quarter 2001 E.F.Y. Ethiopia: Addis Ababa.

Corbridge, S., \& Jones, G. A. (2004). The continuing debate about urban bias: the thesis, its critics, its influence, and implications for poverty reduction. London School of Economics and Political Science, Department of Geography \& Environment.

Das, P. (2017). "Micro, Small and Medium Enterprises (MSME) in India: Opportunities, Issues \& Challenges". Great Lakes Herald, March 2017, Volume 11 Issue No 1

Dorosh, P., Engeda, E., Tamru, S., Tsehaye, E., Debowicz, D., \& Robinson, S. (2011). Ethiopia's Growth and Transformation Plan: A Computable General Equilibrium Analysis of Alternative Financing Options

Garoma, B. F. (2012). Determinants of microenterprise success in the urban informal sector of Addis Ababa: A multidimensional analysis. Ph.D. Dissertation, the Netherlands

Gebre-Egziabher, T., \& Demeke, M. (2005). "Micro Enterprises in Small Town, Amhara Region, Ethiopia: Nature and Performance". Ethiopian Journal of Economics, 14(1), 79-111.

Gobaw, B. Z. (2016). Challenges and opportunities for development in Ethiopia through urban-rural economic linkages (URLs). Doctoral dissertation.

Kihonge, E. (2014). The Role of Small and Medium Enterprises (SMEs) in Small Towns in Rural-Urban continuum: the case of Sagana and Karatina in Mount Kenya Region, Central Kenya. Doctoral dissertation, Clermont-Ferrand 2.

Kniivilä, M. (2007). Industrial development and economic growth: Implications for poverty reduction and income inequality. Industrial development for the 21st century: Sustainable development perspectives, 295333.

Legesse, L., B. (2014). Factors Hindering Industrialization of Ethiopia: The Case of Medium and Large Scale Manufacturing Industries in Major Industrial Zones of Ethiopia. Ph.D. Dissertation, Ethiopian Civil Service University, Addis Ababa

Liedholm, C. (2002) "Small firm dynamics: Evidence from Africa and Latin America", Small Business Economics 18:227-242.

Lipton, M. (1977). Why poor people stay poor: A study of urban bias in world development, London: Maurice Temple Smith

Pedersen, P. O. (1989). The role of small enterprises and small towns in developing and developed countries. CDR project paper, Copenhagen: Center for Development Research.

Tacoli, C. (2004). The role of small and intermediate urban centers and market towns and the value of regional approaches to rural poverty reduction policy.

Tettey, C. (2005). Urbanization in Africa in relation to socio-economic development: A multifaceted quantitative analysis. Doctoral dissertation, University of Akron.

Uribe-Echevarria, F. (1991). "Small-scale manufacturing and regional industrialization". ISS Working Paper Series/General Series, 116, 1-54.

Von Braun. J. (2007). Rural-Urban Linkages for Growth, Employment, and Poverty Reduction. Ethiopian Economic Association: Fifth International Conference on the Ethiopian Economy, June 7-9, 2007.United Nation Conference Center, Addis Ababa.

World Bank (2007).Urban labor markets in Ethiopia: Challenges and prospects, Synthesized Report, Vol.2., (Washington)

UNIDO (2011). Industrial Value Chain Diagnostic: An integrated Tool. United Nation Industrial Development Organization. Vienna, Austria. 